\title{
Episódio Queermuseu: reflexos do despreparo social em torno da Arte
}

\author{
Alessandra Paula Rech ${ }^{1}$ \\ Danielle Schutz ${ }^{2}$
}




\section{Resumo}

Este artigo propõe uma abordagem crítico-reflexiva acerca do analfabetismo visual na sociedade contemporânea, considerando que o despreparo permitiu que a manipulação protagonizada por grupos com interesses políticos levasse ao fechamento da exposição Queermuseu. A análise documental e revisão bibliográfica sugerem que mesmo entre frequentadores e apreciadores de espaços expositivos, há um desconhecimento acerca do papel da Arte. Em um eixo transdisciplinar, autores como Dondis, Cocchiarale, Eco e Hobsbawm fundamentam as investigações acerca dos conceitos e definições sobre Arte contemporânea e a abordagem sobre o processo de construção de linguagens visuais, que vem se desenvolvendo, muitas vezes, distante da formação do público. Foucault, Marcuse, Berman, entre outros na linha da crítica cultural, amparam as considerações a respeito do papel político da Arte e dos instrumentos de alienação que se valem do desconhecimento das massas.

Palavras-chave: Alfabetismo visual, Arte contemporânea, estética, política, censura.

\section{Abstract}

This article aims to propose a reflection critical-reflexive on visual illiteracy in contemporary society considering that the lack of knowledge allowed the manipulation carried out by groups with political interests to lead to the closure of the exhibition Queermuseu. Documentary analysis and bibliographic review suggest that even among visitors and connoisseurs of exhibition spaces, there is a lack of knowledge about the role of art. In a transdisciplinary way, authors like Dondis, Cocchiarale, Eco and Hobsbawm base their research on concepts and information on contemporary art and on the process of constructing visual languages, which is often developing far from the formation of the public. Foucault, Marcuse, Berman, among others in the axis of cultural critique, support considerations about the political role of art and about the instruments of alienation that use the peoples ignorance.

Keywords: Visual literacy, contemporary art, aesthetics, political, censorship.

ISSN: 2175-2346

1 palavrear@gmail.com

2 dschutz@ucs.br 


\section{Introdução}

"O sexo foi aquilo que, nas sociedades cristãs, era preciso examinar, vigiar, confessar, transformar em discurso". (Michel Foucault, 2003)

Há exatos 100 anos da apresentação da Fonte de Duchamp, uma pArte significativa do público que se propõe a apreciar a Arte ainda esboça estranhamento e repulsa diante de obras que não possuem um dado objetivo, definido por Kant (1999) como beleza, mas que ocupam lugar dentro de um espaço expositivo em função do seu caráter conceitual. A exposição Queermuseu: cartografias da diferença na Arte brasileira, realizada no Santander Cultural, em Porto Alegre, com abertura em 15 de agosto de 2017 e curadoria de Gaudêncio Fidélis, provocou uma comoção por pArte de uma parcela do público, que se sentiu ofendida com algumas das obras apresentadas, fato que levou a Instituição a fechar a exposição um mês após seu início.

O objetivo do presente artigo, baseado em metodologia de investigação de campo reflexivo-crítica e revisão bibliográfica e documental, é, à luz de teóricos das Artes e da crítica cultural, avaliar o cenário que propiciou essa reação, em que pesem as limitações do ensino de Arte no Brasil, e os interesses em jogo a partir da espetacularização desse fato. A principal teoria que orienta essa reflexão é a de que o episódio enfatiza um problema recorrente dentro do universo das Artes: a falta de informação por pArte do público sobre o que de fato é a Arte produzida no século $\mathrm{XXI}$, único meio que possibilitaria fazer frente aos interesses de poder manifestados nesse caso.

O percurso desenvolvido aqui é etapa preliminar de pesquisa a respeito do papel do curador na construção de sentido diante de obras artísticas na atualidade, que tem como metodologia a análise de textos de curadoria presentes em exposições realizadas no Rio Grande do Sul. O recorte proposto neste artigo, em um eixo transdisciplinar, se debruça sobre episódios marcantes da história da Arte, bem como as teorias ligadas à estética e à alfabetização visual. Reflete, ainda, sobre o papel do curador como mediador. Por fim, apresenta considerações a respeito das implicações políticas da Arte, na perspectiva da crítica cultural, para apontar a estreita ligação entre ideais estéticos e de dominação, bem como a recorrência da censura no Brasil. Por esse viés, se volta novamente aos fatos ocorridos no episódio de fechamento 3 antecipado da exposição em Porto Alegre, com a finalidade de entender os interesses em jogo nessa intervenção.

\footnotetext{
3 Nota oficial de justificativa do fechamento da exposição: "Nos últimos dias, recebemos diversas manifestações críticas sobre a exposição Queermuseu Cartografias da Diferença na Arte Brasileira. Pedimos sinceras desculpas a todos os que se sentiram ofendidos por alguma obra que fazia pArte da mostra. 0 objetivo do Santander Cultural é incentivar as Artes e promover o debate sobre as grandes questões do mundo contemporâneo, e não gerar qualquer tipo de desrespeito e discórdia (...) Ouvimos as manifestações e entendemos que algumas das obras da exposição Queermuseu desrespeitavam símbolos, crenças e pessoas, o que não está em linha com a nossa visão de mundo. Quando a Arte não é capaz de gerar inclusão e reflexão positiva, perde seu propósito maior, que é elevar a condição humana."
} 


\section{Desenvolvimento}

Ao longo da história da Arte, os novos movimentos que se apresentaram, como Impressionismo, Cubismo e os Ready-made, encontraram uma enorme resistência, tanto por pArte dos apreciadores, quanto dos críticos de Arte. Porém, essas manifestações ocuparam seu espaço, entraram para a história da Arte e deixaram grandes nomes.

No início dos anos 1960, as Artes ainda eram pensadas em duas categorias: a escultura e a pintura, embora já existissem expressões como a fotografia e a performance. Em 1962, o presidente do Departamento de Arte da Universidade da Califórnia, Lester D. Longman, publica na revista Artforum uma crítica a respeito da Action painting, como as mulheres nuas de Yves Klein, que usavam seus corpos para imprimir tinta em grandes painéis brancos. Longman não repudiava a existência desse tipo de manifestação artística, e sim o fato de ela estar ganhando espaço e visibilidade no meio.

A popularização dessas manifestações, incluindo a Assemblage, técnica que une colagens com materiais tridimensionais, dá origem a outros movimentos como o Minimalismo e o Pop Art, representado pelo o artista Andy Warhol e suas latas de sopa Campbell. Para Archer, por mais que tais objetos produzam Arte, eles jamais perdem sua identificação com o mundo cotidiano de onde foram tirados.

Duchamp pedia que o observador pensasse sobre o que define a singularidade da obra de Arte em meio à multiplicidade de todos os outros objetos. Seria alguma coisa a ser achada na própria obra de Arte ou nas atividades do artista ao redor do objeto? (ARCHER, 2012, p. 3).

Se Duchamp ou o Salão dos Independentes tivesse se rendido às inúmeras críticas que ocorreram no passado, provavelmente o que conhecemos por Arte contemporânea teria hoje outra face, ou se encaixaria num modelo pouco perturbador, a ponto de o observador procurar apenas beleza e qualidade técnica nas obras.

\section{Alfabetismo visual}

Desde a infância somos motivados a ler e a escrever, mas não recebemos o mesmo estímulo a respeito da leitura e interpretação de imagens. Segundo Dondis (2003), grande pArte da comunicação visual foi deixada ao sabor da intuição e do acaso. Dessa forma, ao experimentar obras de Arte que enfatizam temas considerados tabus, ou mesmo que tratem de assuntos repudiados pela grande maioria das pessoas, o observador sequer se questiona sobre o porquê de tais manifestações, não há um preparo, ou alfabetismo visual, que o faça perceber uma obra de forma questionadora, e não simplesmente com um olhar de reprovação não fundamentada.

Existe, porém, uma enorme importância no uso da palavra "alfabetismo" em conjunto com a palavra "visual". A visão é natural; criar e compreender mensagens visuais é natural até certo ponto, mas a eficácia, em ambos os níveis, só pode ser alcançada através do estudo. (DONDIS, 2003, p. 17) 
As crianças não são preparadas para aprender a ver, o foco da educação encontrase no sistema verbal. A disciplina de Artes visuais, que deveria ensinar os sujeitos a lerem imagens, por vezes sequer trabalha os conteúdos básicos do currículo de Artes, como história da Arte, percepção espacial, Gestalt, semiótica, etc.

A Missão artística francesa, que em 1816 implantou a primeira escola de Artes no Brasil, chamada de Escola Real de Ciências, Artes e Ofícios, chamada de Imperial Academia Escola de Belas Artes a partir de 1826, está nas origens da recorrente visão elitizada a respeito do estudo da Arte. Comandada por artistas europeus que obedeciam ao estilo neoclássico, seu objetivo era oficializar o ensino de Artes no Brasil de forma acadêmica. O que inicialmente deveria ser uma escola de ofícios, abordando áreas como desenho técnico para operários, passou a ser frequentada pela aristocracia, que aspirava absorver os ideais de beleza europeia. Tal elitização contribui, até os dias de hoje, para a incompreensão que se verifica no episódio em análise.

O reconhecimento da necessidade de tornar o ensino de Artes acessível encontra amparo na Constituição Federal de 1988, que prevê, em seu artigo 206, parágrafo II, na seção sobre Educação: "O ensino tomará lugar sobre os seguintes princípios (...) liberdade para aprender, ensinar, pesquisar e disseminar pensamento, Arte e conhecimento."

O fato de a Arte ser mencionada no texto constitucional só foi alcançado por meio das lutas dos Arte-educadores, que na década anterior já buscavam politizar a questão, e foram em busca de condições para a qualificação para futuros professores de Artes, a fim de obter um maior resultado com os alunos dentro do ambiente escolar. O papel do Arte-educador, portanto, é o de estimular o aluno a se desenvolver e se conscientizar acerca do seu processo criativo, a ponto de o habilitá-lo a pensar sobre a Arte e sua influência nos demais segmentos da sociedade.

Para Dondis (2003), não sendo considerada, equivocadamente, área de conhecimento fundamental ao desenvolvimento humano, estudar Artes, ou mesmo estudar imagens, não pressupõe uma necessidade importante ao desenvolvimento cognitivo do indivíduo no sistema. Dessa forma, um fato recorrente em muitas escolas é o preenchimento do período de Artes com atividades diversas, como jogos e brincadeiras, ou mesmo a aplicação de atividades, como pintar lacunas, por professores que não possuem formação em Artes.

Uma das tragédias do avassalador potencial do alfabetismo visual em todos os níveis da educação é a função irracional, de depositário da recreação, que as Artes visuais desempenham nos currículos escolares, e a situação parecida que se verifica no uso dos meios de comunicação, câmeras, cinema, televisão. Por que herdamos, nas Artes visuais, uma devoção tácita ao não-intelectualismo? (...) Até mesmo a utilização de uma abordagem visual do ensino carece de rigor e objetivos bem definidos. Em muitos casos, os alunos são bombardeados com recursos visuais - dispositivos, filmes, slides, projeções audiovisuais - mas tratase de apresentações que reforçam sua experiência passiva de consumidores de televisão. (DONDIS, 2003, p. 17-19)

Ciente dessas deficiências, Dondis entendia ser provável que o alfabetismo 
visual, que pode ser muito bem explorado na disciplina de Artes, se tornasse, no último terço do século XX, um dos paradigmas fundamentais da educação. Porém, na prática, passadas mais algumas décadas, o ensino em Artes está se deslocando para o caminho inverso.

Ana Mae Barbosa (2016), pioneira na Arte-educação no Brasil, em entrevista, afirma que a desobrigatoriedade do ensino de Artes visuais, que ocorreu com a mudança pela qual passou o atual sistema de ensino, prejudica não só a percepção visual, mas os estímulos racionais e afetivos de crianças e adolescentes, uma vez que a Arte ajuda a criar um ensino ativo, ao atuar sobre o indivíduo em sua percepção, capacidade crítica e resposta criadora.

Em coluna na revista eletrônica Fórum, Wilson Ferreira destaca que, por trás da reforma que flexibiliza o ensino de Arte e de educação física, há um plano de se valer, justamente, do analfabetismo visual e da falta de consciência corporal como ferramentas de controle:

\footnotetext{
Não basta apenas o golpe político. É necessária uma operação psicológica para anestesiar as outras amargas "flexibilizações" que serão proximamente enfiadas goela abaixo da sociedade. Uma operação para manter um sistema de comunicação projetado pela ditadura militar e mantido até hoje - a concentração das informações para a opinião pública exclusivamente nas mídias audiovisuais, especialmente a TV. Para isso é necessária a manutenção do analfabetismo visual: a crença ingênua de que ver é um ato natural e fisiológico, impossibilitando a educação do olhar e a percepção das intencionalidades por trás das mensagens visuais (FERREIRA, 2016).
}

\section{Estética}

Grande pArte do público apreciador de Arte espera encontrar beleza nas obras que observa, não tendo o conhecimento prévio de que a experiência estética da qual irá fazer pArte pode tanto estar nas sensações de belo, quanto no estranhamento que as obras lhe provocam. O conceito de beleza universal está intimamente ligado àquilo que é agradável ou bom.

O ideal de estética na Grécia antiga priorizava a representação de corpos proporcionalmente elaborados, principalmente nas esculturas. Eco (2015) reforça essa ideia quando afirma que o objeto belo é aquele que, em virtude de sua forma, deleita os sentidos, em particular o olhar e a audição. A escultura grega não idealizava um corpo abstrato, mas buscava uma beleza ideal, operando uma síntese de corpos vivos, na qual se exprime a beleza psicofísica que harmoniza a alma e o corpo, ou seja, a beleza do corpo e a bondade da alma.

Conforme Dondis (2003), nossa reação àquilo que vemos é natural e ocorre sem esforço, não precisamos de um estudo prévio para reagirmos a um estímulo visual, mas somos influenciados e modificados por estados psicológicos, condicionamentos culturais e experiências ambientais.

Por meio da sintaxe da linguagem visual, é possível analisar como os indivíduos 
recebem e expressam as mensagens visuais. Dentro dessa linha são apresentados diversos pressupostos para que uma imagem seja considerada bela e harmônica. A aplicação de regras como nivelamento, aguçamento, uso de retas em diagonal, uso de cores complementares ou análogas pode provocar uma sensação de conforto visual, a ponto de o observador aceitá-la como uma representação de beleza.

Para Dondis (2003), há três níveis de captação e expressão dessas mensagens: o representacional - aquilo que vemos e identificamos com base no meio ambiente e na experiência; o abstrato - a qualidade cinestésica de um fato visual reduzido a seus componentes visuais básicos e elementares, enfatizando os meios mais diretos, emocionais e mesmo primitivos da criação de mensagens, e o símbolo - vasto universo de sistemas de símbolos codificados que o homem criou arbitrariamente e ao qual atribuiu significados.

Estética vem do grego "aisthesis", que significa "faculdade de sentir" ou "compreensão pelos sentidos". A palavra aisthesis tem a mesma origem da palavra aistheticon que significa "o que sensibiliza", ou seja, que afeta os sentidos. Já a beleza é a percepção individual de características que são agradáveis aos sentidos. Alguns aspectos referentes a essas características são universais, enquanto outros são restritos a: culturas, sociedades e períodos de tempos específicos. Assim, pelo viés do sentido, uma obra não precisa ser necessariamente bela para ser apreciada.

\footnotetext{
Faz-se um quadro distribuindo-se pigmentos sobre um pedaço de tela, mas a imagem criada não é a somatória do pigmento e da estrutura da tela. A imagem que emerge do processo é uma estrutura de espaço, e o próprio espaço é um todo emergente de formas, de volumes coloridos e visíveis. A mensagem e o significado não se encontram na substância física, mas sim na composição. A forma expressa o conteúdo: artisticamente bom é tudo aquilo que articula e apresenta um sentido a nossa compreensão. (DONDIS, 2003, p. 132)
}

Kant (1999) diz que a experiência do belo não comporta nenhum tipo de conhecimento, seja ele histórico, científico ou filosófico, porém, admite que a Arte inclui emoções, paixões e sentimentos. Dessa forma, o olhar de um observador despreparado para uma obra perturbadora está sujeito a juízos de valor que podem ser condicionados pelo seu meio.

A beleza clássica está relacionada à ideia de proporção, como as produções de Leonardo Da Vinci, que se utilizou da Proporção Áurea em seus estudos. Essa fórmula ainda é largamente utilizada por artistas e designers, e mesmo quando não se apresenta um cálculo explícito, garante uma harmonização perceptível pelo observador.

A estética da proporção assumiu formas sempre mais complexas e podemos reencontrá-las também na pintura. Todos os tratados das Artes figurativas, dos bizantinos, dos monges Athos ao Tratado de Cennini (séc XV), revelam a ambição das Artes plásticas de alcançar o mesmo nível matemático da música. (ECO, 2002, pg 87).

Essa perfeição atinge a precisão máxima na perspectiva renascentista, sendo usualmenteignorada pelos próximos movimentos artísticos, comoo Barroco, Realismo, Impressionismo e principalmente, as Artes a partir do século XX. Tais movimentos, 
chamados de vanguarda, utilizavam a "beleza da provocação", manifestada através de um experimentalismo artístico, do Futurismo ao Cubismo. Nesse ponto, já não existe mais o problema da beleza, pois se entende que as novas imagens são artisticamente relevantes e, portanto, devem proporcionar o mesmo prazer que uma escultura grega.

A Arte já não se propõe a fornecer uma imagem da Beleza natural, nem quer proporcionar o pacífico prazer da contemplação de formas harmônicas. Ao contrário, deseja ensinar a interpretar o mundo com olhos diversos, a usufruir do retorno a modelos arcaicos ou exóticos, ao universo do sonho ou das fantasias dos doentes mentais, às visões sugeridas pelas drogas, à descoberta da matéria, à reproposição desvairada de objetos de uso em contextos improváveis. (ECO, 2002, p. 417).

Em Obra aberta, Eco (1962, p.22) aponta que o valor das obras de Arte contemporâneas está na ambiguidade que as caracteriza. Mesmo livre, teoricamente, dos conceitos clássicos de beleza, a Arte seguirá polêmica em diversos momentos da história.

\section{Arte e política}

A respeito das questões estéticas, Paviani (2003) aponta que os modelos da cultura de elite passam a ser imitados através de um falso refinamento, de um esteticismo que prega o belo pelo belo, ignorando a dimensão real do mundo e a dimensão ética do homem.

A Arte culta sofre concorrência do fenômeno Kitsch, que pode ser definido como uma desagregação da função estética. O problema não é simplesmente o do gosto estético, mas o da educação estética, do significado objetivo e subjetivo da Arte e das manifestações culturais. E, em última instância, o de voltar à cultura real do homem concreto, no seu dia a dia, com suas angústias e esperanças.

As considerações de Paviani seguem a linha de Marcuse, que aponta a relação entre os padrões estéticos e a ideologia da sociedade burguesa, uma vez que a afirmação do belo e sua persistência (cultura afirmativa) é também um aparato totalitarista:

Seu traço decisivo é a afirmação de um mundo mais valioso, universalmente obrigatório, incondicionalmente confirmado, eternamente melhor, que é essencialmente diferente do mundo de fato da luta diária pela existência, mas que qualquer indivíduo pode realizar para si 'a partir do interior', sem transformar aquela realidade de fato (MARCUSE, 1997, p. 95-96).

Em obra posterior, Marcuse define que as buscas artísticas, desde os anos 30, vão no sentido de estabelecer a linguagem artística como linguagem revolucionária: "Isso implica o conceito de imaginação como faculdade cognitiva, capaz de romper o feitiço do establishment" (2005, p. 261).

O filósofo Marshall Berman, que em alguns momentos de sua crítica da Modernidade aponta o caráter apocalíptico de Marcuse como prejuízo ao reconhecimento de que as relações sociais são dinâmicas, por outro lado assume 
uma recorrente dificuldade de adesão do público ao universo simbólico da Arte, na cultura que se estabelece após a Revolução Industrial:

Jackson Pollock imaginou suas pinturas gotejantes como florestas onde os
espectadores podiam perder-se (e, é claro, achar-se) a si mesmos, mas em
geral nos esquecemos a Arte de nos pormos a nós mesmos nas pinturas, de nos
reconhecermos como participantes e protagonistas da Arte e do pensamento de
nossa época. Nosso século fomentou uma espetacular Arte moderna; porém, nós,
parece que esquecemos como apreender a vida moderna de que essa Arte brota.
O pensamento moderno, desde Marx e Nietzsche, cresceu e se desenvolveu de
vários modos; não obstante, nosso pensamento acerca da modernidade parece ter
estagnado e regredido. (BERMAN, 1986, p.24)

A ideia de retrocesso, tão difundida nos embates políticos dos últimos anos, não é nova: Berman (1986) já observava essa tendência. Segundo ele, as polarizações básicas se manifestam exatamente no início do século XX.

O indivíduo que foi alfabetizado visualmente de forma precária, ou inexistente, não conhece seu espaço para construção do sentido de uma obra, e tampouco a experimenta por meio das emoções que lhe provocam. Seu discurso acaba se focando na atribuição de valores, ou na preocupação que, recorrentemente, se traduz pela expressão: "o que o artista quis dizer?".

\section{Mediação e curadoria}

Para Hobsbawm (2012), o escândalo provocado pelo urinol de Duchamp se encaixava no movimento Dadaísta, que se transformou no/ou antecipou o Surrealismo, rejeitando toda a Arte que não tinha características formais, embora tomasse emprestados alguns truques das vanguardas Cubista e Futurista pré-1914. Qualquer coisa que pudesse causar perplexidade entre os amantes da Arte burguesa convencional era dadaísmo aceitável.

Embora os Ready-mades de Duchamp provocassem estranhamento, no século anterior o artista francês Gustave Courbet escandalizou o mundo da Arte com a pintura nomeada $A$ origem do mundo, em que pArte do corpo de uma mulher nua estava exposto com a genitália em destaque.

Obras que usam o corpo e a sexualidade como protagonistas de expressão artística também já horrorizaram o público. Artistas como o austríaco Rudolf Schwarzkogler (1941-1969), que realizava performances de automutilação, a ponto de amputar seu próprio pênis enquanto era fotografado em uma delas, e o artista Vito Acconci (19402017), que mordia a si mesmo, ou passava horas vestindo o seu pênis com roupas de bonecas, alegando que estava dividindo seu eu em dois, já provocaram repulsa em seus públicos. Essa reação, por vezes, não ultrapassa a esfera da crítica ao artista que produziu determinada Arte. As reais motivações e as mensagens que essa Arte busca produzir não são sequer questionadas.

Usar a sexualidade como meio de impactar ou chamar a atenção para outras questões, que sequer poderiam ser levantadas não fosse por conta da provocação, 
é um recurso utilizado de forma recorrente na Arte. A Arte contemporânea passou a recorrer a materiais orgânicos como forma de expressar o caráter efêmero de suas obras. Secreções como menstruação ou sêmen já figuraram em produções artísticas. Um exemplo polêmico é a obra do artista inglês Marc Quinn, que em 1991 produziu uma réplica de sua cabeça feita com 4,5 litros de seu próprio sangue.

Fazer uso de materiais não convencionais é um recurso utilizado para sair do formato e atingir a reflexão, ou, no mínimo, o estranhamento do público. Ainda de acordo com Dondis:

O resultado final é a verdadeira manifestação do artista. O significado, porém, depende da resposta do espectador, que também a modifica e interpreta através da rede de seus critérios subjetivos. Um só fator é moeda corrente entre o artista e o público, e, na verdade, entre todas as pessoas - o sistema físico das percepções visuais, os componentes psicofisiológicos do sistema nervoso, o funcionamento mecânico, o aparato sensorial através do qual vemos. (2003, p. 31).

A contrapartida do público não acontece por despreparo e sujeição a um sistema alienante, desde os bancos escolares até as formas de entretenimento vigentes, que se valem da passividade e da espetacularização da realidade, em detrimento de sujeitos críticos.

Um público que espera visitar um espaço expositivo para contemplar o belo pode acabar frustrado, pois a Arte contemporânea pode oferecer a representação de cenas do cotidiano. Temas como morte, frustrações e dores humanas são recorrentes, e muitas vezes apresentados com grande carga de dramaticidade, explorada por meio de um realismo perturbador.

Para Mário Pedrosa (1997), a Arte plástica ainda é, para o público, uma imitação da natureza, a representação da realidade através de certos cânones codificados desde a Renascença. Nesse contexto, a figura do mediador, presente em diversos espaços expositivos, é bastante procurada por quem espera por uma definição verbal para obras com significados menos explícitos. Há casos em que o visitante sequer tenta se relacionar com a obra, pArte imediatamente em busca da mediação, para só então olhar com maior atenção e envolvimento.

Em observações assistemáticas na fase inicial dessa pesquisa, realizadas em Porto Alegre, Rio Grande do Sul, foi possível observar o discurso de muitos visitantes, que por diversas vezes utilizavam o modelo tradicional de Arte, como pinturas e esculturas com iconografia distante de qualquer polêmica, como parâmetro para o que era, e o que não era considerado Arte.

É fato que o mediador atua de forma importante quando passa ao público informações acerca da vida do artista, seu local de atuação e seu contexto histórico, mas pretender dar a significação da obra prejudica a fruição estética do observador, causando um afastamento de sua percepção em relação à Arte contemporânea.

Embora a Queermuseu tenha sido alvo de críticas e ofensas, a ponto de alguns visitantes produzirem dentro do Santander Cultural vídeos que expressavam sua revolta, durante a observação dessa exposição (que ocorreu dia 9 de setembro de 2017, ironicamente, um dia antes do fechamento) não foram presenciadas ofensas 
direcionadas aos mediadores ou críticas expressas às obras.

Para Cocchiarale (2006), uma das práticas mais generalizadas no mundo institucional das Artes, compreendendo aí o chamado grande público, é a necessidade de mediação pela palavra para a produção de sentido. Não se trata das teorias da Arte, tanto históricas quanto filosóficas, cuja generalidade e universalidade só poderiam ser produzidas pelo discurso. O que está em questão é a busca ansiosa pela explicação verbal de obras reais e concretas, como se, sem a palavra, fosse impossível entendêlas.

Ainda segundo Cocchiarale (2006), quando mal feita, uma visita guiada pode estimular o público ao desejo de entender a obra, o que significaria reduzi-la à esfera do inteligível. Quando o educador estimula o público a se relacionar com a obra e senti-la, desfaz-se a necessidade de socorro do suposto farol da opinião daqueles que sabem: historiadores, filósofos, críticos, artistas, curadores... O artista contemporâneo convoca para um jogo onde as regras não são lineares, mas desdobradas em redes de relações possíveis ou não de serem estabelecidas.

Sob esse aspecto, é possível questionar até que ponto o discurso do mediador poderia ter contribuído para a aceitação do público em relação à Queermuseu. Os mediadores dessa exposição estariam preparados para enfrentar o público que se revoltou com as obras? Quais seriam seus argumentos para conduzir o observador? Tais questões ficam abertas para a continuidade dessa investigação.

A resistência apresentada, não só na Queermuseu, mas em relação à Arte contemporânea, não se restringe apenas à parcela do público que não tem um conhecimento prévio acerca do assunto, mas é possível afirmar que grande pArte de educadores de Artes visuais compartilham desse estranhamento frente a obras que necessitam de experimentação, uma vez que as questões educacionais no que concerne à Arte já atravessam gerações - e culminam com os anos de ditadura no Brasil, como veremos adiante.

Esse desconforto que muitos espectadores experimentam pode atuar como um convite, desde que lhes seja estimulada essa autonomia, trabalho que poderia ser explorado pelo mediador bem orientado e, evidentemente, por um sistema educacional que trabalhasse a autonomia de pensamento como um todo.

Falar em experimentação na Arte contemporânea é desconstruir um conservadorismo que se coloca em posição de defesa diante das manifestações, é rever a ideia de que apenas através da mediação pela palavra uma produção apresentará sentido.

A respeito da curadoria, Marília Panitz (2016), coordenadora do programa educativo do Centro Cultural Banco do Brasil (CCBB), afirma que a tarefa do curador é fazer o distanciamento e gerar possibilidades de leitura para a obra, apontando possibilidades de composição de uma sentença, sempre cuidando que haja respeito ao contexto original.

Curadoria consiste na pesquisa, seleção, organização e montagem de uma exposição. O curador - que tem um papel fundamental enquanto mediador cultural é essencial dentro das dinâmicas do sistema da Arte. Cabe ainda ao curador o papel de 
gestor cultural, e mesmo de produtor, no caso daqueles que trabalham com projetos independentes.

[...] o conceito de curadoria passou a desempenhar um papel central em relação ao estudo, organização e visibilidade dos acervos de Arte e da produção artística, com especial ênfase para a produção contemporânea. Dessa forma, a definição de curadoria ganhou atributos novos que trouxeram para este cenário a supervalorização das atividades expositivas das coleções e dos acervos, a possibilidade de articulação com os próprios autores das obras e um protagonismo sem precedentes que se mistura com o mercado de Artes, com os canais de comunicação e com a projeção social. (BRUNO, 2015, p.6).

O ofício de curador exige pesquisa, crítica e reflexão constante. A concretização de um projeto só é possível a partir da relação e negociação com profissionais de áreas como design de interiores, arquitetura, iluminação, conservação etc. Ao mesmo tempo em que situa o observador de diferentes níveis de conhecimento acerca da Arte contemporânea, o texto de curadoria corre o risco de interromper a fruição estética no momento em que apresenta o sentido das obras de forma explícita. Lyotard (1986, p. 165) afirma: "o alvo da exposição é preciso: despertar as ansiedades e reflexões sobre a condição pós-moderna no visitante."

O texto curatorial divide espaço com as obras, não apresentando uma ordem pela qual o espectador deveria seguir, de modo que fica a seu critério iniciar a visita tanto pela leitura do texto, quanto pela apreciação das obras. No entanto, ao iniciar pela leitura de um texto que "explica" a motivação do artista, o confronto e a perplexidade que essa Arte busca causar no público podem ser prejudicados.

\section{Censura}

Uma vez que o artista contemporâneo busca uma aproximação com a vida real, espera-se que o público reaja a esse confronto. No caso da exposição Queermuseu, a reação ocorreu de forma violenta, embora muitos artistas desse coletivo já tivessem seus nomes consagrados no meio artístico, como por exemplo a artista Adriana Varejão, que já teve suas obras expostas em Bienais de São Paulo, além de participar de exposições em Londres e Nova lorque.

Na pintura Cena de interior II, de 1994, uma das obras mais atacadas da exposição, Varejão representou cenas de diversos tipos de práticas sexuais que, segundo ela, pretendiam apenas colocar em evidência eventos que não são comumente discutidos.

As obras da série Criança viada, de autoria de Bia Leite, anteriormente expostas no XIII Seminário LGBT, no ano de 2016, em Brasília, foram acusadas de incentivar a prática da pedofilia, uma vez que apresentam crianças erotizadas e com características que seriam próprias de adultos. O furor que se estabeleceu pareceu ainda maior por se tratar de crianças. A autora defende suas obras com a argumentação de que crianças que apresentam distinções de gênero merecem receber um olhar de respeito para com suas identidades.

Foucault (2003), ao analisar os mecanismos de poder na sociedade, já apontava 
o uso da sexualidade infantil, uma vez que o sexo das crianças tornou-se "ao mesmo tempo um alvo e um instrumento de poder".

Alguns vídeos de espectadores ofendidos com a Queermuseu circulam pela web. Em um deles, o visitante passa pelas obras apenas reclamando da imoralidade e falta de vergonha daquilo que está sendo exposto. Seu discurso é repetitivo ao qualificar apenas a "safadeza" das obras, em momento algum ele levanta a hipótese do porquê da existência de tais obras. Em outros, pessoas promovem discursos de ódio aos artistas e àqueles que os financiaram, bem como às instituições que os acolheram. O argumento fortemente apresentado é o da imoralidade e da falta de qualidade artística das obras, discursos que sequer levantam a hipótese de entender o que uma exposição como essa busca provocar. ${ }^{4}$

Os discursos de ódio contra a exposição foram fortemente influenciados pelo posicionamento do MBL, organização política sem fins lucrativos de extrema direita, que ora se autodenomina "liberal", ora "conservadora," e que em diversos momentos se posicionou de forma radical nas chamadas "guerras culturais", mobilizando milhares de grupos e pessoas até mesmo contra as cotas raciais, sob a alegação de estarem atuando a favor da causa liberal.

Evidencia-se, dessa forma, uma situação de censura amparada em duas questões cruciais: de um lado, uma sociedade despreparada para o entendimento da Arte; de outro, o oportunismo de grupos emergentes no poder. Ainda em Foucault:

O sexo sempre foi o núcleo onde se aloja, juntamente com o devir de nossa espécie, nossa 'verdade' de sujeito humano. A confissão, o exame de consciência, toda uma insistência sobre os segredos e a importância da carne não foram somente um meio de proibir o sexo ou afastá-lo o mais possível da consciência: foi uma forma de colocar a sexualidade no centro da existência e de ligar a salvação ao domínio de seus movimentos obscuros. (2003, p. 229-230)

Essa valorização da intimidade como instrumento de poder se evidencia no episódio de fechamento da exposição, ironicamente em tempos em que a nudez na publicidade é naturalizada - e favorável à economia "liberal".

Arespeito dos desentendimentos em torno do papel da Arte, Bourriaud demonstra

\footnotetext{
4 Queermuseu: cartografias da diferença na Arte brasileira é uma exposição que explora a diversidade de expressão de gênero e a diferença na Arte e na cultura contemporâneas através de um conjunto de obras que percorrem um arco histórico de meados do início do século 20 até a contemporaneidade. Abolindo a cronologia e adotando uma série de mecanismos de justaposição que possibilitam o confronto produtivo entre obras de períodos diversos, a exposição promove 0 questionamento entre a realidade material e conceitual das obras e seus paralelos na atualidade, valendo-se de uma abordagem sobre a diversidade e diferença sob uma perspectiva de gênero e os inúmeros desdobramentos que este adquire. 0 conceito da exposição, de um "museu provisório" representa uma porta de entrada para discutir questões relativas à formação do cânone artístico e a constituição da diferença. Exposições possibilitam que experienciemos os diversos paralelos entre a Arte, seu potencial criativo e o campo da cultura. Nesse universo, as obras de Arte mostram-nos que a diversidade, expressa na constituição da diferença como alteridade, surge igualmente refletida tanto na estruturação do cânone artístico quanto no modo como ele é estabelecido pela academia e pelo museu. Dessa forma, Queermuseu institui um museu provisório, ficcional e metafórico, onde a inclusão é exercida para além dos parâmetros restritivos das prerrogativas canônicas, geralmente excludentes e discriminatórias. Para essa plataforma curatorial, a escolha das obras levou em conta os aspectos artísticos, culturais e históricos dos objetos, considerando seu potencial de impacto dentro e fora da exposição, enfatizando sobretudo sua contribuição para o espectador contemporâneo. Ao exibir obras de diferentes periodos, estilos e inclinações estéticas lado a lado, o que se pretende é destacar a importância da vocação histórica para a compreensão da atualidade, e não apenas transpor o espectador através de um "túnel do tempo" para o passado. Essa estratégia tem por objetivo trazer essas obras para o presente por meio de um rasgo epistemológico temporal e conceitual que ingressa no tempo presente como uma intervenção no conhecimento. Queermuseu é, acima de tudo, uma exposição que visa dar projeção à Arte e à cultura, abordando inúmeras questões artísticas que ultrapassam os mais diversos aspectos da vida contemporânea na constituição formal dos objetos, dos hábitos, dos costumes, da moda, da diversidade comportamental e geracional, da evolução da estética, da percepção da cor, dos desdobramentos do corpo, e de várias outras manifestações que, em última análise, são determinantes na construção da Arte. Sua contribuição para uma história de exposições no contexto mundial merece ser assinalada e é propiciada por juntar-se a um ainda restrito número de exposições sobre o assunto no contexto global. Trata-se da primeira exposição com essa abordagem realizada no Brasil e a primeira com essa dimensão na América Latina. Gaudêncio Fidélis - curador.
} 
que questões aparentemente já superadas ocupam a cena, em consequência da falta de embasamento.

Críticos e filósofos, em sua imensa maioria, não gostam de abordar práticas contemporâneas. Assim elas se mantêm essencialmente ilegíveis, pois não é possível perceber sua originalidade e sua importância analisando-as a partir de problemas resolvidos ou deixados em suspenso pelas gerações anteriores $(2009$, p.9)

A escritora e documentarista Eliane Brum, em reportagem para o jornal El País, defende a ideia de que o ataque à exposição foi uma forma de apagamento que episódios como esse ajudam a produzir e a perpetuar, como o número assombroso de homossexuais assassinados e de estupros de mulheres no país. Ao denunciar a Arte e os artistas como "pedófilos", o que se produz é o apagamento de um fato bastante incômodo: o de que a maioria das crianças violadas é violada por familiares e conhecidos.

A respeito dessa característica de apagamento nas sociedades mediadas, Debord discorre em 1968:

(...) a discussão vazia do espetáculo - isto é, sobre o que fazem os donos do mundo - é organizada pelo próprio espetáculo: destacam-se os grandes recursos do espetáculo, a fim de não dizer nada sobre o seu uso. Em vez de espetáculo, preferem chamá-lo de domínio da mídia. Com isso querem designar um simples instrumento, uma espécie de serviço público que gerenciaria com imparcial "profissionalismo" a nova riqueza da comunicação de todos por mass media, comunicação que teria enfim atingido a pureza unilateral, na qual se faz calmamente admirar a decisão já tomada. (DEBORD, 1997, p. 3).

Um detalhe significativo é que não havia faixa etária recomendada para a visitação, indicativo de que não havia nas obras nada que incentivasse a zoofilia e tampouco o sexo de crianças. Em nota ao jornal El País, reportagem de Heloísa Mendonça (2017), o Santander Cultural reconheceu que, além de despertar polêmica saudável e o debate sobre grandes questões do mundo atual, infelizmente a mostra foi considerada ofensiva por algumas pessoas e grupos, e a gestão pediu desculpas a todos aqueles que enxergaram o desrespeito a símbolos e crenças na exposição. Afirma ainda que o ocorrido não faz pArte da sua visão de mundo, nem dos valores que "a instituição" prega, e, por esse motivo, decidiu por fechar a mostra antecipadamente.

Na mesma reportagem, o curador da exposição, Gaudêncio Fidélis, afirmou que a instituição não apresentou um posicionamento firme, tampouco defendeu a permanência da exposição. Diante das mais de 17 mil manifestações, em sua maioria negativas, o Santander se rendeu à censura.

A exposição, que já estava aberta ao público há 23 dias, teve mais de 1,5 mil visitantes em sua abertura e, em 13 dias, contou com a presença de mais de 27 mil espectadores e nenhum tipo de manifestação. Segundo Fidélis, o MBL, apoiado pelo prefeito da cidade, foi quem provocou o ataque em prol do fechamento, além de incentivar o fechamento de contas dos correntistas do banco.

Historicamente, a Arte já sofreu inúmeras formas de censura, como o juízo 
final no teto da Capela Sistina. Pintadas por Michelangelo, as cenas que procuravam comunicar a fé possuíam diversas figuras humanas desnudas, fato que levou o Concílio de Trento a determinar a cobertura das pArtes ofensivas. Esse ato foi imposto em 1559 pelo Papa Pio V, que determinou que Daniel Volterra, discípulo de Michelangelo, deveria pintar nas figuras os panos que ficaram conhecidos como bragas.

No Brasil, há precedentes históricos que servem de alerta. Segundo Stephanou (2001, p. 14), a censura, principalmente sobre as produções artísticas e culturais, no período de 1964 a 1968, não foi "assistemática e eventual", mas "constante, multifacetada, violenta e desmanteladora".

Entre os fatos que caracterizavam o "vazio cultural", no período e nos anos subsequentes, apontados por Zuenir Ventura (2000), estavam o desaparecimento da polêmica e da controvérsia cultural. O período ditatorial causou a evasão dos melhores cérebros. A submissão, condição para a continuidade no contexto, tomou conta das Artes e o exercício político ficou atrelado à moral, a uma forma conservadora de ver a vida. Passadas mais de três décadas do fim do regime militar no Brasil, atos como o fechamento da Queermuseu evidenciam o desconhecimento acerca da importância da liberdade de expressão e, principalmente, do valor do papel transgressor e polêmico da Arte contemporânea.

\section{Considerações finais}

Embora muitas das obras da Queermuseu que causaram reações negativas no público já tivessem sido expostas em outros momentos, dois fatores mostraram-se relevantes para o fechamento antecipado da exposição: o analfabetismo visual, ou seja, o desconhecimento do propósito da Arte contemporânea, e o uso político do episódio por grupos emergentes aos poder, valendo-se desse desconhecimento das massas. Um observador bem preparado para esse tipo de experimentação poderia se sentir provocado e até mesmo horrorizado com tais obras, seria a partir daí possibilitada a produção de sentido, que o artista deixa a cargo do espectador. Assim, seu discurso teria outra fundamentação que não fosse apenas o da imoralidade. Ações como a do MBL não encontrariam um campo fértil em um público mais bem preparado para entender que a Arte contemporânea pretende atuar sobre o sujeito reflexivo, e não promover a prática de crimes sexuais.

O fechamento da exposição não pode ser considerado uma consequência da provocação apresentada pela Arte, uma vez que ela se ocupa em estimular o público a pensar sobre as questões apresentadas, e experimentar a obra de Arte em um nível sensível que vai além da simples observação. Qualificar a Queermuseu como meio de incentivar o sexo com crianças ou animais é, além de falta de conhecimento do propósito da Arte contemporânea, uma forma de manipular as massas menos esclarecidas, a fim de que problemas sociopolíticos sejam ignorados.

A Queermuseu obteve um resultado improvável, uma vez que ao longo da história da Arte, muitas manifestações artísticas foram consideradas ofensivas e imorais, e nem por isso foram fechadas. Da mesma forma que Duchamp se destacou 
ao escandalizar o mundo de então, na repercussão causada pela Queermuseu, artistas e obras ganharam grande visibilidade, mas não por seu trabalho, qualidade técnica ou capacidade de promover a reflexão, e sim, por estarem inseridos no evento que foi propositadamente transformado em escândalo. Resta à sociedade fortalecer as bases culturais para capacitar o público, e os próprios agentes culturais, a resistir diante de episódios como esse.

\section{Referências}

ARCHER, M. Arte contemporânea. Uma história concisa. São Paulo: Mundo da Arte, 2012.

BARBOSA, A. M. 'A Arte ajuda a criar um ensino ativo', diz Arte educadora pioneira. Gaúcha ZH. Porto Alegre, 29 de outubro de 2016. Disponível em <https://gauchazh. clicrbs.com.br/porto-alegre/noticia/2016/10/a-Arte-ajuda-a-criar-um-ensinoativo-diz-Arte-educadora-pioneira-8046706.html>. Último acesso em 31.10.2017.

BRASIL. Constituição (1988). Constituição da República Federativa do Brasil. Organização de Alexandre de Moraes. 16.ed. São Paulo: Atlas, 2000.

BERMAN, M. Tudo que é sólido desmancha no ar. São Paulo: Companhia das Letras, 1986.

BOURRIAUD, N. Estética relacional. São Paulo: Martins Fontes, 2009.

BRUM, E. Gays e crianças como moeda eleitoral. El País: São Paulo, 18.09.2017. Disponível em <https://brasil.elpais.com/brasil/2017/09/18/opinion/1505755907_773105.html>. Acesso em 31.10.2017.

BRUNO, M.C.O. Definição de curadoria: os caminhos do enquadramento, tratamento e extroversão da herança patrimonial. Ibermuseus.org, Brasília, 2015. Disponível em http://www.ibermuseus.org/wp-content/uploads/2015/07/Unidad1Texto_ Definicao-de-Curadoria.pdf. Último acesso em 4 de novembro de 2017.

COCCHIARALE, F. Quem tem medo da Arte contemporânea?. São Paulo: Massaganda, 2009.

DEBORD, G. A sociedade do espetáculo e Comentários sobre a sociedade do espetáculo. Trad. bras. Estela dos Santos Abreu. Rio de Janeiro: Contraponto, 1997.

DONDIS, D. A. Sintaxe da linguagem visual. São Paulo: Martins Fontes: 2003.

ECO. U. História da beleza. São Paulo: Record, 2015.

História da feiúra. São Paulo: Record, 2015.

Obra aberta. São Paulo: Perspectiva, 2007

FERREIRA, W. A agenda secreta da reforma do ensino: o analfabetismo visual. Revista Fórum: São Paulo, 25 de setembro de 2016. Disponível em https://www.revistaforum. 
com.br/cinegnose/2016/09/25/1763/. Acesso em 30 de novembro de 2017.

FIDÉLIS, G. In MENDONÇA, H. Queermuseu: o dia em que a intolerância pegou os expositores para Cristo. El País: São Paulo. 13.09.2017. Disponível em https://brasil. elpais.com/brasil/2017/09/11/politica/1505164425_555164.html. Acesso em 31 de outubro de 2017.

FIORAVANTE, C. Marc Quinn dá sangue à escultura. Folha de S. Paulo. São Paulo, 23 de fevereiro de 1998. Disponível em http://www1.folha.uol.com.br/fsp/ilustrad/ fq23029829.htm. Acesso em 5 de novembro de 2017.

FOUCAULT, M. Microfísica do poder. São Paulo: Edições Graal, 2003.

GASPARI, E; HOLLANDA, H. B; VENTURA, Z. Cultura em trânsito. Da repressão à abertura. Rio de Janeiro: Aeroplano, (2000).

HOBSBAWM, E. A era dos extremos. Companhia das Letras, São Paulo, 1995.

KANT, I. Crítica e estética na modernidade. São Paulo: Editora Senac, 1999.

LONGMAN, L. D. Conformity and the arts. I: 1. Artforum: Nova York, 21 jun. 1962.

MARCUSE, H. Cultura e sociedade. v1. Tradução de Wolfgang Leo Maar, Isabel Maria Loureiro, Robespierre de Oliveira. São Paulo: Editora Paz e Terra, 1997.

A Arte na sociedade unidimensional. In LIMA, L. C. (org). Teoria da cultura de massa. São Paulo: Editora Paz e Terra, 2005.

PAVIANI. J. Estética mínima. Notas sobre Arte e literatura. Porto Alegre: Edipucrs. 2003.

PEDROSA, M. Norma e percepção estética. São Paulo: Edusp, 1997.

STEPHANOU, A. A. Censura no regime militar e militarização das Artes. Porto Alegre: Edipucrs, 2001. 
